\title{
«FIGURA DE APARIÇÃO». IBN ‘ARABĪ E(M) LLANSOL
}

João Barrento (Espaço Llansol)

Recebido a 15/11/2018. Aceite a 12/4/2019.

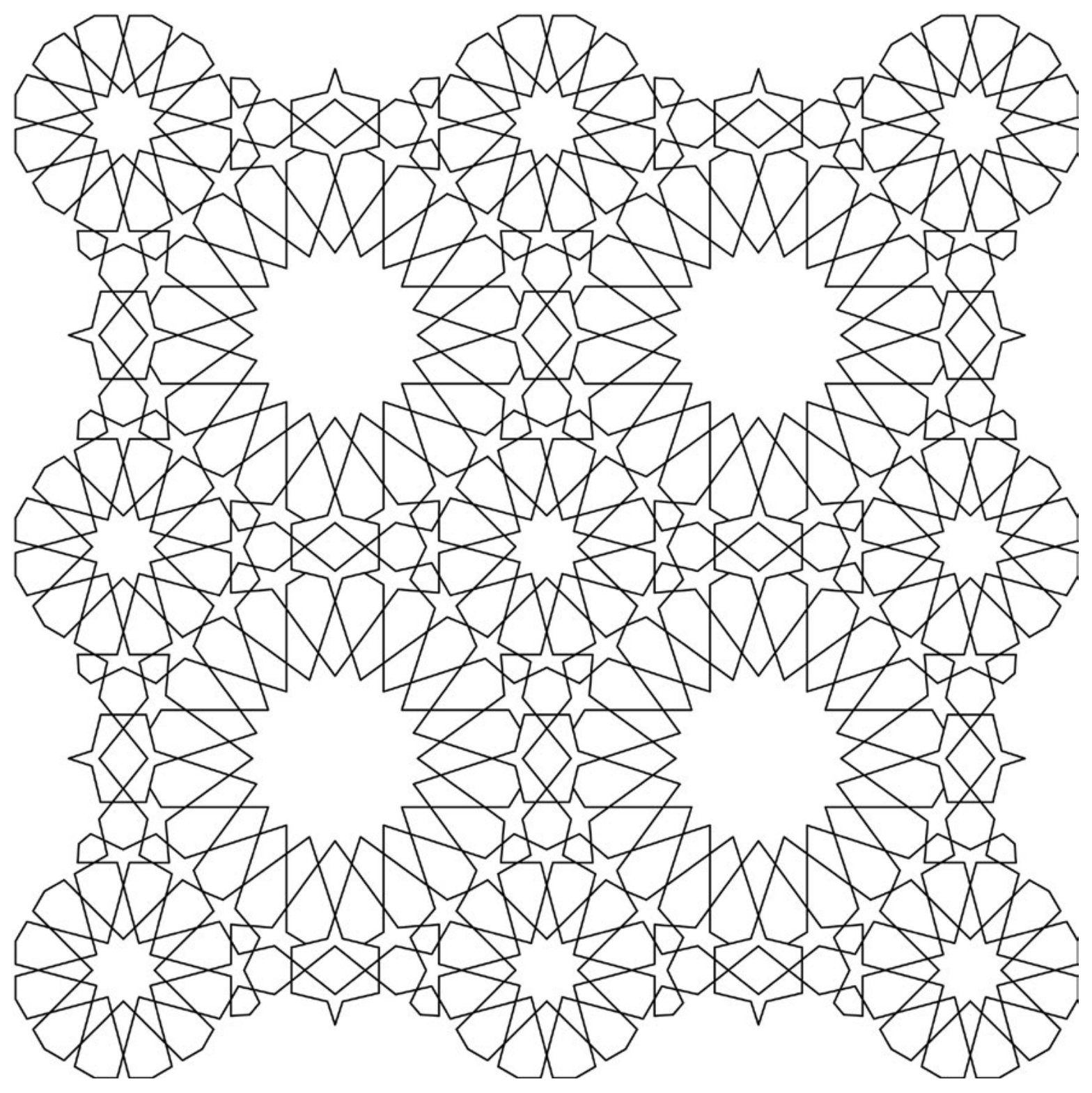


Quando ${ }^{1}$, no Diário Finita, naquele que é referido como «o tempo de Ibn 'Arabî», este entra no quarto da casa onde Nezam dormita, seminua, e se inicia um momento, escritural e imaginal, de «magnificação do feminino»², o místico de Múrcia assumiu já plenamente um perfil figural, deixando de ser, como noutras passagens da escrita de Llansol, mera referência a uma figura histórica conhecida pouco antes através de fontes indirectas, sobretudo o livro de Henry Corbin, L'imagination Créatrice dans le Soufisme d'Ibn' Arabi $\hat{\imath}^{3}$. Um tal «perfil figural», porém, não se constrói apenas a partir dos traços da figura que nos são oferecidos por essa magnífica cena fulgor dos dias 25 e 26 de Abril de 1977. Ibn 'Arabī voltará a estar presente nas leituras e na escrita diária de Llansol ao longo dos anos oitenta e ainda noventa, e os registos desse convívio permitem ampliar a imagem de Ibn 'Arabī enquanto figura llansoliana a uma série de outros traços que procurarei ir reconstituindo e comentando a seguir, tendo em pano de fundo quatro momentos (não necessariamente sequenciais), que têm essencialmente a ver com os seguintes aspectos constitutivos da Figura em Llansol:

1. A sua inserção numa unidade múltipla do Ser (essa espécie de água lustral onde ela respira) e aquilo que, a partir do filósofo Emanuel Levinas, é designado como o Há, uma forma de Presença, fundo e referência discreta no devir da Figura em Comunidade (e em geral, para Llansol, na singularidade das coisas mergulhadas na imanência, numa «signografia do Há» ${ }^{4}$ que alimenta as figuras - e a escrita da sua criadora);

2. O papel da imaginação activa e a sua função noética: este é provavelmente o foco inicial da atracção de Llansol por Ibn 'Arabī. De facto, desde muito cedo há anotações sobre o mundus imaginalis e a imaginação que «faz conhecer» ${ }^{5}$;

3. O lugar dos místicos na Comunidade das Figuras e a importância do mútuo nessa visão da Comunidade;

4. A doutrina do Amor sem objecto e do Amante, e sua possível ligação às noções do Ambo ou do «amor impan». Esta problemática do amor e do Amante, mais desenvolvida no diário Finita, concentra de certo modo em si já todas as outras, e por isso me centrarei mais nela.

1 Publica-se, com o presente texto, a intervenção no Colóquio A Imaginação do Amor. Llansol e Ibn 'Arabī, na Faculdade de Letras de Lisboa, 20 e 21 e Junho de 2017.

2 Maria Gabriela Llansol, Finita, fot. Duarte Belo, posf. Augusto Joaquim, Lisboa, Assírio \& Alvim., 2005, pp. 187-213.

3 Henry Corbin, L'imagination créatrice dans le soufisme d'Ibn' Arabî, Paris, Flammarion, 1958. Existe um exemplar na biblioteca de M. G. Llansol.

4 M. G. Llansol, Inquérito às Quatro Confidências, Lisboa, Relógio D’Água, 199-, p. 141.

5 Id., Livro de Horas, vol. II, Um arco singular, ed. João Barrento, Maria Etelvina Santos, colab. Maria Carolina Fenati, Lisboa Assírio \& Alvim, 2010, p. 40. 
Quando, em 1977, Maria Gabriela Llansol «descobre» ${ }^{6}$ Ibn 'Arabī, através do livro de Henry Corbin, tem atrás de si, acabada de publicar, a obra que renovou a sua escrita e o seu olhar sobre o mundo e sobre a História, O Livro das Comunidades. O misticismo, representado por figuras como João da Cruz ou Mestre Eckhart, instalou-se então na sua Obra para nunca mais a abandonar. Por esses anos dá-se igualmente o encontro com Spinoza e a sua filosofia, também ela de algum modo teofânica e libertadora, uma filosofia da imanência e da mediação entre mundos, da unidade corpo-alma e de um eudemonismo de raiz, um pensamento que facilmente se encontra com o teomonismo (que Corbin encontra em Ibn 'Arabī) - podíamos também dizer, lembrando Musil, com o misticismo do dia claro -, imagético e cordial de Ibn 'Arabī. O místico de Múrcia manter-se-á discretamente vivo (e mesmo renovado) no universo escritural de Llansol durante quase duas décadas, até ao terceiro Diário, Inquérito às Quatro Confidencias, onde reaparece para narrar o episódio da «palmeira de Sevilha» ${ }^{7}$ - típico do universo sufi, pelo lugar de mediador directo que o Profeta nele assume com a sua bênção salvadora. Ibn 'Arabī, figura de aparições pontuais, mais do que de presença contínua (como João da Cruz, Spinoza ou Pessoa-Aossê), faz aí a sua última entrada no universo da escrevente Llansol, que anota: «Ibn 'Arabî - para me lançar no Há vivo - veio de Damasco, onde repousa há setecentos e cinquenta anos» ${ }^{8}$. Mas esse será também, como mais adiante percebemos, o momento da tomada de consciência, e fixação no texto, de um princípio de misticismo laico (não muito distante da polaridade do grande Vazio vs. Presença de Deus em Ibn 'Arabī ou Eckhart), que guia a nossa autora desde sempre: «Não há bênção. / É o que se diz quando se fala em Deus ausente. O nosso há é viator e faber.»9. Ora, este é, de facto, o princípio condutor da Figura em Llansol: temos uma travessia (metamórfica e de risco) a cumprir, e nela agimos, e agindo mudamos. E nessa travessia, a que Llansol chama também «metanoite» ${ }^{10}$, «o texto é o órgão imaginal de quem escreve.» ${ }^{11}$.

É por esta via de um «órgão imaginal» - e não imaginário, ficcional ou fantástico -, que será o instrumento de uma função noética, de conhecimento, e não alienante ou irreal, da imaginação, que Llansol entra, com Henry Corbin, e depois com a leitura de alguns textos do místico sufi, no universo de Ibn 'Arabī. O mundus imaginalis, essa região do entre-ser e das ideias-imagens em Ibn 'Arabī, «onde o espiritual toma corpo e o corpo se torna espiritual» ${ }^{12}$, será, de facto, determinante para a sua escrita e para o nascimento progressivo, sempre amplificado, de uma Comunidade figural baseada

6 Sobre Ibn 'Arabī e o processo da descoberta, cf. Ibid., pp. 41-42.

7 Id., Inquérito às Quatro Confidências, cit., pp. 95-96.

8 Ibid., p. 93.

9 Ibid., p. 96.

10 Id., Na Casa de Fulho e Agosto, Geografia de Rebeldes III, seguido de O Espaço Edénico, posfácio de João Barrento, Lisboa, Relógio D’Água, 2003, p. 143.

11 Id., Lisboaleipzig, Lisboa, Rolim, vol. II, p. 168.

12 Id., Livro de Horas, vol. III, Numerosas linhas, ed. João Barrento, Maria Etelvina Santos, colab. Maria Carolina Fenati, Lisboa Assírio \& Alvim, 2013, p. 285. 
nos princípios do «mútuo» (que não se limita a ser matéria de simples relação na ordem do comum, mas é uma verdadeira «conversação espiritual», diz Augusto Joaquim, no sentido da unio sympathetica, da sym-pathia activa entre os seres na comunidade sufi dos «Fiéis do Amor», diferente da unio mystica do misticismo extático ou nupcial) ${ }^{13}$. A ideia do «mútuo» engloba mesmo uma ideia de confrontação produtiva no interior da comunidade, e uma dialéctica do semelhante e do diferente, do comum e do diverso, do solitário e do comunitário, que deve muito à leitura dos místicos (entre eles já Ibn 'Arabī) que marca a fase inicial da Obra de M. G. Llansol. A lei da comunidade em Llansol, como a dos «Fiéis do Amor» (expressão que Augusto Joaquim, significativamente, utiliza como título da sua versão teatral d' O Livro das Comunidades em 1996) é a da existência sem limites, dos seres sem distinção (uns em relação aos outros), num espaço oceânico sem margens a que se chama Lugar - o deserto da metanoite, espaço extremo destituído de supérfluo, vazio e essencial, disponível e de risco. Um outro nome desta comunidade é em Llansol «o jardim que o pensamento permite» (e há sem dúvida ecos de Ibn 'Arabī neste jardim!), nome que me traz à memória uma página de um dossier dactiloscrito (já de 2000, curiosamente com o título «Sobre o dorso de um camelo») em que somos confrontados com a «visão real» de um Lugar que é porventura o dessa comunidade, lugar do invisível no visível, barro desse jardim, espaço do outro e do fulgor da relação que poderia ser tradução de um poema ou de uma «iluminação» de Ibn 'Arabī. Transcrevo duas passagens dessa página:

_Lá no deserto um lugar oculto que se oculta dos demais, quando aparece. É um lugar-pessoa___ réplica incomparável do jardim que o pensamento permite. É o barro desse jardim [...]

Subitamente, aí, o dia aparece e desaparece, sempre mais obstinado e descendo sobre si mesmo; caminha pela areia até encontrar o lugar onde os animais sobem ao céu e trazem ao resplendor as colinas, ou seja, as dunas - corpo do incerto.

Estou à janela vendo rodopiar a minha visão real. O Sol emudece, e o camelo tem-no agora sobre o dorso, vestindo-lhe o pêlo sem o queimar. E sem queimar meus olhos. «Este lugan», pensei, «é mais do que um lugar do raciocínio. É o lugar em que o outro é minha amada ou amado, que importa?, se o outro esplende na corrente vária, cheia de afluentes do meu próprio pensamento, que, como qualquer outro pensamento desperto, é o lugar que o fulgor permite / é o lugar onde irrompe o fulgons. ${ }^{14}$

A partir dos anos setenta, a escrita-vida de Llansol não abandonará este modo imaginal, e não conceptual, de conhecimento do mundo com e para uma Comunidade cujos pilares são, entre outros, o do «eterno retorno do mútuo» ${ }^{15}$, da «conversação espiritual» e dos «encontros de confrontação» com vista a uma contínua «magnificação» - da alma, do saber de, do corpo, do Feminino (aqui com a intervenção explícita de Ibn 'Arabī-Figura, como veremos a seguir).

13 Cf. Id., Lisboaleipzig, cit., vol. 1, pp. 148-152.

14 Espólio de M. G. Llansol, Dossier dactiloscrito DO A31, p. 74.

15 M. G. Llansol, Inquérito às Quatro Confidencias, cit., pp. 95-96. 
Logo num dos primeiros Cadernos de escrita lemos a seguinte frase lapidar: «Mergulhei no mundus imaginalis e deixei-me aí viver a minha vida» ${ }^{16}$. E depois, apoiando-se em Henry Corbin: «Não se tratará de fantasia, profana ou não, nem do órgão que segrega um imaginário identificado com o irreal, nem mesmo daquilo que consideramos ser um órgão da criação estética. Tratar-se-á de uma função absolutamente fundamental, submetida à ordem de um universo que lhe é próprio, dotado de uma existência perfeitamente 'objectiva', em que o imaginário é o verdadeiro órgão da percepção» ${ }^{17}$. A força de autonomia desta forma de imaginação activa na criação da comunidade textual é grande, e Llansol tem consciência disso, quando anota num caderno de 1978, parecendo ecoar o clássico «Não meu, não meu é quanto escrevo», de Fernando Pessoa: «A minha "imaginação criadora" é distinta de mim mesma: é a sombra que acompanha aquela que escreve» ${ }^{18}$.

Nas suas aparições, breves mas intensas, no texto de Llansol, a figura de Ibn 'Arabī nasce aí sob o signo de um aparente paradoxo: servir «a experiência do vazio», alimentando ao mesmo tempo «a dilatação do ver» ${ }^{19}$. Pouco antes, e naquele que é o primeiro registo em que o místico sufi é nomeado $^{20}$, este surge na companhia de Eckhart e da sua visão da criança que vem para libertar Deus da sua solidão infeliz. A via desta polaridade - entre a constatação de um Vazio absoluto e a possibilidade (necessidade?) de um acesso a ele pelo caminho do «ver», de um conhecimento imaginal-imaginante que em Ibn 'Arabī corresponde a uma «teosofia na imanência» ${ }^{21}$ e em Llansol a uma «signografia do Há» ${ }^{22}$-, essa via parece ser, tanto a da Figura como a da própria Maria Gabriela Llansol no seu processo de busca e de descoberta de uma «norma» própria a partir de O Livro das Comunidades (e que implica, entre outras coisas, a revisão de todo um percurso espiritual anterior, que se situava nos limites de uma religiosidade mais convencional e institucional).

Essa norma é, no que à noção de «Figura» se refere - e nela cabe também Ibn 'Arabī - a do devir móvel a partir de uma configuração histórica mais ou menos estática. Por isso Llansol pode escrever, numa passagem inédita de um dossier dactiloscrito: «Há, sobre o Ibn 'Arabî descrito na Encyclopaedia Universalis, Todo-um-Saber, mas eu saberei infinitamente mais.» ${ }^{23}$.

16 Espólio de M. G. Llansol, Caderno 1.03, p. 253.

17 M. G. Llansol., Livro de Horas, vol. II, cit., p. 237.

18 Espólio de M. G. Llansol, Caderno 1.04, p. 209, em 5 de Janeiro de 1978.

19 M. G. Llansol, Finita, cit., p. 188.

20 Ibid., p. 143, em 23 de Dezembro de 1976.

21 Halil Bárcena, Sufismo. Barcelona, Fragmenta Editorial, 2012, p. 107. No presente artigo, as traduções de textos originais em outras línguas, para a língua portuguesa, são do autor do artigo, salvo diferente indicação.

22 M. G. Llansol, Inquérito às Quatro Confidencias, cit., p. 141.

23 Espólio de M. G. Llansol, Dossier dactiloscrito DO A06, p. 62. 
O que «sabe mais» Maria Gabriela Llansol? Sabe que uma figura da sua escrita não o é antes de o ser, que ela vem de um lugar não-figural, de um espaço (histórico) não textual, de um tempo (também histórico, ou puramente empírico-cronológico) que não participa (ainda) da ucronia trans-histórica do Texto. Devém-se figura deixando para trás a condição estática da personagem, para aceitar entrar num espaço-tempo outro (um «lugar», uma paisagem anímica) onde impera a «lei ligeira e breve» ${ }^{24}$ da metamorfose e da troca verdadeira, tornando-se assim um princípio activo dotado de energia própria, uma força actuante.

O «mais saber» de Llansol em relação a Ibn 'Arabī, ao trazê-lo para o seu texto, é aquele que lhe permitirá transformá-lo neste sentido - como fará com tantos outros: Baruch/Bento em mestre de um saber da alma; Mestre Eckhart em cozinheiro de alimentos espirituais; Hadewijch de Antuérpia na encarnação da sensualidade místico-erótica; Nietzsche no «homem do livro» e num «pré-póstumo»; Aossê-Pessoa verdadeiramente num outro-de-si-mesmo, para lá de toda a heteronímia... Neste processo de anular ou recobrir uma imagem para que outra se possa ir revelando ou emergindo com traços novos através do trabalho de uma «imaginação figural», Ibn 'Arabī surgirá, dispersamente, quer como aquele que tem nome (histórico), quer como imagem ou forma figural sem Eu, com a designação de o Amante (como Khezr [Hidr], o mestre dos sem mestre, para os sufis: indivíduo e arquétipo num só). No Diário Finita, nos episódios em que Ibn 'Arabī é figura central, esta problemática do Amante que «jamais alguém terá ${ }^{25}$ ou do nome sem identidade clarifica-se, com evidentes ecos da leitura de Ibn 'Arabī.

Aí lemos, por exemplo: «O Amante não pode ser uma pessoa, ou seja, máscara que a si mesma se assume como agente vivo ou personagem de um destino próprio. $\mathrm{O}$ Amante não pode ser alguém $[\ldots]{ }^{26}$. Em Ibn 'Arabī, o amante é manifestação concreta e evanescente d'Ele, o Amado. Aqui, em Llansol, é o sustentáculo do amor do amor, do amor sem objecto, como nas Elegias de Rilke («O amor do Amor», lemos num avulso de 1993, «não será a simples oblação gratuita?»»" $)$. Amor sem objecto, sem Forma, sem Face(s). Apenas desejo e vontade. É o que leio nestas passagens (de 1977) sobre o enigma do Amante em que Ibn 'Arabī (o de algumas das Iluminações - as Futūhāt - e o de O Intérprete do Desejo Ardente (Tarğumān al-Aš̌wāq) claramente se atravessa:

O Augusto diz-me que o Amante jamais alguém o terá [...] O intento do seu movimento é levar o amado a dispensar a forma do amor e da beleza [...] Vê-se assim que o Nome Enigmático tem um movimento específico: expulsar a Face, na progressiva audição do enigma. Ouvir o Nome sem o ligar a uma Face, a um sexo, a uma forma particular. ${ }^{28}$

24 Espólio de M. G. Llansol, Caderno 1.58, p. 5.

25 M. G. Llansol, Finita, cit., p. 207.

26 Ibid., p. 206.

27 Espólio de M. G. Llansol, Caderno 2.49, avulso 02.

28 M. G. Llansol, Finita, cit., p. 207. 
O Amante, como o próprio Deus, é uma ipseidade, Ele-mesmo-sempre-outro. Por isso um comentador do Livro das Contemplações Divinas ${ }^{29}$ lembra a importância do léxico pronominal em Ibn 'Arabī e na escola de Bagdad no contexto deste «mistério da ipseidade» e da «luz do espanto» (que em Llansol tanto pode ser a que se destaca do mundo e das suas «dobras que apuram o silêncio» como a do «fulgor que há nas coisas»). Também ela recorre com frequência ao «léxico pronominal» des-subjectivante - o Ele, o Esse, o Alguém - que culmina na transformação do nome de Deus em -Eus, evocando a multiplicidade de Faces, que é também do Amante, para lá do Nome.

E à pergunta: «Mas o que é então o Amante?», responde-se - ainda com Ibn 'Arabī e a sua tripartição do amor em divino, espiritual e natural -, apontando para uma ideia claramente espiritualizada dessa noção-chave para a definição da Figura, à luz do «mútuo» ou do «ambo»: o Amante é «o teu sexo caminhante para além da repulsa» ${ }^{30}$; ou, num caderno de 1985, «uma força de luar» (certamente «libidinal» $)^{31}$, ou ainda «o que há de mais raro à face da Terra / do desejo, tal como o pobre saciado» ${ }^{32}$.

E no dia seguinte do Diário, e em termos ainda mais iluminantes, ao sobrepor o agir, a vontade actuante, o «quem me chama» ao «quem sou», ao mero ser ou ter limitativos, diz-se: «Caminho, e não sou caminhante» ${ }^{33}$. Deste aparente paradoxo emerge ainda mais claramente a imagem mística, sensual-espiritual do Amante:

E assim penetro mais além no carreiro que me conduz a uma clareira, onde chego, sempre acompanhada por esta intuição da presença não sentimental do Amante.

Que era, pois, Ele, ali presente, me presenciando?

Não-água, como eu, mas marulhando como nós, eu e a água.

Não pássaro, mas pipilando.

Não caminhante, mas indo.

$\mathcal{N a ̃ o - p e s s o a , ~ m a s ~ p r e s e n c ̧ a ~ a c t i v a , ~ m a n i f e s t a n d o - a ~ p o r ~ a c t o s ~ s u c e s s i v o s ~ e ~ e f e ́ m e r o s ~ d e ~ t e n s a ̃ o . ~}{ }^{34}$

É uma quase-visão de Llansol, como a que encontro, noutro registo, mas ainda e sempre seguindo uma dialéctica bipolar (em termos de interior-exterior, sensível-espiritual, manifestação imanenteessência ou substância, corpo-alma...), numa anotação a lápis (de 2005) na página de anterrosto de uma versão francesa do grande mestre sufi persa Suhrawardī intitulada L'archange empourpé [O arcanjo

29 Cf. Ibn 'Arabî, Le livre des contemplations divines, ed. Stéphane Ruspoli, Arles, Actes Sud, 1999, pp. 22-23.

30 M. L. Llansol, Finita, cit., p. 208.

31 Espólio de M. G. Llansol, Caderno 1.19, p. 4.

32 Espólio de M. G. Llansol, Dossier dactiloscrito DO A08, p. 36, 22 de Outubro de 1988 ?

33 M. G. Llansol, Finita, cit., pp. 187-213 (texto do dia 2 de Maio de 1977).

34 Id., Finita, cit., pp. 210-211. 
$\vdots$

purpúreo/vestido de púrpura $]^{35}$, que reúne tratados e narrativas místicas; a passagem é um bom exemplo da subtil continuidade e quase indistinção, tão frequente em Llansol, entre a leitura e a escrita:

Projectou-se na página uma estreita faixa rubra que era o reflexo do sangue interior/escondido que corria nos meus dedos. Era como o óleo do meu corpo ali-eu nunca tinha visto tal beleza. E fechei o livro, e apaguei a luz, e fiquei a dormir, sem dormir nem meditar___ no devaneio de que a luz enrubesce e interioriza o sangue.

$\mathcal{N}$ o meio da noite escurecida tropeçamos nas tábuas de leitura e os ritmos se sucedem num caudal de imaginalização criadora. Um ritmo humaníssimo me surpreende, celestial e pesado, humano e leve, pois as trocas se intensificavam na procura.

Há nesta anotação momentos que se aproximam da ideia da revelação divina em Ibn 'Arabī como fenómeno «perspectivista», como a luz incolor que ganha cores na refracção do cristal, sendo essa «coloração» particular sempre produzida para os olhos dos recipientes ${ }^{36}$. As páginas sobre o Amante em Finita, uma glosa llansoliana do tema da Sophia aeterna a partir do episódio de Nezam em Meca e do Intérprete do Desejo Ardente, são aquelas em que M. G. Llansol dá forma escrita mais explícita à «lição» de Ibn 'Arabī tornado figura do seu próprio texto. Essas páginas de Finita são a variante llansoliana da união indissolúvel, de raiz sufi, entre o amor e o conhecimento. Esta é a versão sufi e xïita do «eterno feminino» que encontrará expressão moderna, antes de Llansol, por exemplo em Goethe e Novalis (não por acaso dois seguidores de Spinoza e divulgadores da sua filosofia, então marginalizada ou esquecida). O «Coro místico» final do Fausto (e já antes o episódio de Helena de Tróia) é uma das expressões mais acabadas do lugar do Feminino como motor do impulso criador e de conhecimento, objecto de desejo sensual e sobretudo de elevação espiritual. Lembro essas linhas finais do Fausto de Goethe:
Chorus Mysticus:
Tudo o que passa
É símbolo só;
O que não se alcança
Em corpo aqui está;
$O$ indescritivel
Realiza-se aqui;
O Eterno-Feminino
Atrai-nos para si. ${ }^{37}$

35 Cf. Suhrawardī, L'archange empourpré: quinze traités et récits mystiques, tr. Henry Corbin, Paris, Fayard, 1976.

36 Cf. Marie-Madeleine Davy, Encyclopédie des mystiques. Paris, Seghers, 1977, t. 2, p. 487.

37 Johann W. Goethe, Fausto, tr. João Barrento, rev. Anabela Prates Carvalho, Lisboa, Relógio d'Água, 2013, $2^{a}$ ed., vv. 1204-1211. 
Também em Novalis, no núcleo de fragmentos intitulado «Sophie, oder über die Frauen» [Sofia, ou sobre as mulheres] a sombra de Ibn 'Arabī parece estar presente em fragmentos como: «O coração é a chave do mundo e da vida»; «Estamos sós com tudo o que amamos»; «Será a mulher a finalidade do homem? E é a mulher sem finalidade?»; ou ainda, lapidarmente: «O amor pode, por meio da vontade absoluta, transformar-se em religião» ${ }^{38}$.

Não apenas no diário Finita, mas também em muitas outras passagens editas e inéditas da Obra de Llansol por que fomos passando, e onde o Šayh al-Akbar apela à reflexão ou suscita escrita, fomos também assistindo à configuração de um perfil llansoliano do místico de Múrcia em que convergem muitos traços da noção llansoliana de «Figura», e também horizontes e temáticas que definem a natureza singular da sua escrita e do pensamento que a suporta, reflectidos em textos e leituras de e sobre Ibn 'Arabī. O Šayh acabará por ocupar, nos momentos de presença mais intensa na paisagem escritural de Llansol, um lugar muito especial na «geografia dessa linhagem» ${ }^{39} \mathrm{com}$ a qual Llansol se identifica, e que é a das suas figuras maiores. Naquela que será a última das anotações dos diários manuscritos em que Ibn 'Arabī é nomeado, lemos:

10 de Fevereiro de 2006

Ibn Arabî, Nietzsche, Spi [noza] - meus familiares, nem próximos nem distantes, presentes em qualquer devaneio; ouço o tambor de seus textos, seus fios textuais.

Ao reuni-los, vou tentando que eles, de diferentes épocas, não sejam reunidos numa geração perdida. ${ }^{40}$

Estamos na fase de escrita do último livro publicado por Maria Gabriela Llansol, Os Cantores de Leitura, para onde converge quase toda a plêiade de figuras que atravessaram a sua Obra ao longo de três décadas. E esta última menção do nome do místico de Múrcia é, na verdade, uma referência iluminante a uma tríade de peso entre as muitas figuras dessa geografia de afinidades na Obra desta autora singular.

38 Novalis, Fragmentos são Sementes, tr. e introd. João Barrento, Lisboa, Roma, 2006.

39 M. L. Llansol, Lisboaleipzig, cit., p. 139.

40 Espólio de M. L. Llansol, Caderno 1.72, p. 181. 


\section{REFERÊNGIAS BIBLIOGRÁFIGAS}

BÁRCENA, Halil (2012), Sufismo, Barcelona, Fragmenta.

CORBIN, Henry (1958), L'imagination créatrice dans le soufisme d'Ibn’ Arabî, Paris, Flammarion.

DAVY, Marie-Madeleine (1977), Encyclopédie des mystiques, t. 2, Paris, Seghers.

GOETHE, Johann W. (2013), Fausto, tr. João Barrento, rev. Anabela Prates Carvalho, Lisboa, Relógio d'Água, $2^{\mathrm{a}} \mathrm{ed}$.

IBN 'ARABI (1999), Le livre des contemplations divines, ed. Stéphane Ruspoli, Arles, Actes Sud.

LLANSOL, Maria Gabriela (2013), Livro de Horas, vol. III, Numerosas linhas, ed. João Barrento, Maria Etelvina Santos, colab. Maria Carolina Fenati, Lisboa Assírio \& Alvim.

(2010), Livro de Horas, vol. II, Um arco singular, ed. João Barrento, Maria Etelvina Santos, colab. Maria Carolina Fenati, Lisboa Assírio \& Alvim.

(2005), Finita, fot. Duarte Belo, posf. Augusto Joaquim, Lisboa, Assírio \& Alvim.

(2003), Na Casa de Julho e Agosto, Geografia de Rebeldes III, seguido de O Espaço Edénico, posf. de João Barrento, Lisboa, Relógio D’Água.

(1994), Lisboaleipzig, 2 vols., Lisboa, Rolim.

(199-), Inquérito às Quatro Confidências, Lisboa, Relógio D’Água.

NOVALIS (2006), Fragmentos são Sementes, tr. e introd. João Barrento, Lisboa, Roma.

SOHRAWARDI (1976), L'archange empourpré: quinze traités et récits mystiques, tr. Henry Corbin, Paris, Fayard. 